\title{
BEHAVIOURAL SCIENCE EVIDENCE IN CHILD SEXUAL ABUSE PROSECUTIONS IN SOUTH AFRICA: A JURISPRUDENTIAL AND COMPARATIVE INSIGHT
}

\author{
GP Stevens \\ LLB LLM LLD
}

Senior lecturer, Department of Public Law

University of Pretoria

EC Lubaale

LLB LLM

\section{SUMMARY}

The role of behavioural science (BSE) in proving the occurrence of child sexual abuse (CSA) is well documented. Equally, its role in placing the evidence of the CSA victim into proper perspective is undisputable. South Africa stands out as one of the very few or perhaps the only criminal justice system in Africa which has over the years admitted BSE in CSA prosecutions. This potentially makes it a source of good practice for many criminal justice systems in Africa and the world over. Despite the many years of admitting BSE in CSA prosecutions, little is known about the critical role it has played thus far, the gaps in the courts' current approach to BSE and how these gaps can be addressed. The present article, with reference to selected recent case law from South Africa and comparative case law from America, analyses the critical role of BSE in affording broader redress to CSA victims. The article identifies the gaps in the current approach of the courts in South Africa. Drawing from the approach of selected courts in America, it suggests additional reforms which may be relevant if the potential of BSE in CSA prosecutions is to be fully and appropriately exploited.

THE PROBLEM OF CHILD SEXUAL ABUSE AND THE PROSECUTION'S EVIDENTIARY CHALLENGES

The extremely high incidence of CSA in South Africa is well documented. ${ }^{1}$ Children are exposed to various forms of sexual abuse, ranging from less severe abuses such as fondling of the genitals or breasts, forcing or

Richter "Baby Rape in South Africa" 2003 Child Abuse Review 392-400; Schepers et al "'Adolescents' Constructions of Gender and Sexuality" 2012 New Voices in Psychology 2338; Finkelhor "The International Epidemiology of Child Sexual Abuse" 1994 Child Abuse Research \& Neglect 409-417; and Muller and Holly Introducing the Child Witness (2009). 
manipulating the child into fondling, attempted rape, to more severe abuses such as oral rape, anal rape, finger penetration, penetration with objects and rape. $^{2}$ The South African Police Service (SAPS) crime reports indicate that a staggering percentage of sexual offences are committed against children with the majority of the perpetrators being acquaintances. ${ }^{3}$ The judiciary which consistently interfaces with CSA cases describes the problem as "a cancer" in South Africa's society. ${ }^{4}$ Regrettably, despite the extremely high incidence of CSA, conviction rates remain relatively low. ${ }^{5}$ There is an evident gap between the incidence of CSA and the conviction rates. This gap has been described by Conradie and Tanfa as a "criminal justice bottleneck" whereby many cases are reported, but the numbers decrease when the perpetrators are arrested, charged, prosecuted and sentenced. ${ }^{6}$ There is a formidable and wellestablished body of empirical research demonstrating that most CSA cases are not supported by medical evidence. ${ }^{7}$ Yet for many criminal justice systems, the presence of medical evidence is a major determining factor in the decision to prosecute. As Kreston rightly puts it, "the absence of medical corroboration infers the absence of either a prosecutable case or of proof beyond a reasonable doubt" in most CSA cases. ${ }^{8}$ By implication, the current position brings to the fore the critical need for the criminal justice systems to broadly accommodate other forms of evidence if sexual offending against children is to be effectively proved.

\section{THE ROLE OF BSE IN DETERMINING THE ISSUE OF WHETHER CSA ACCURRED (DIAGNOSTIC EVIDENCE)}

There is no standard definition of BSE. Bagshaw defines it as "the branch of science concerned with the advancement of knowledge by the observation of the behaviour of subjects in response to stimuli". "As it pertains to CSA

2 Niekerk "At the Coalface: The Child Line Experience" in Richter et al (eds) Sexual Abuse of Young Children in Southern Africa (2004) 268.

3 South African Police Service (SAPS) Annual Crimes Report 2011/2012 "An Analysis of the National Crimes Statistics" (2012) 5-20.

$4 \quad$ S v Swartz 1999 (2) SACR 380 (C).

5 Jewkes et al "Medico-legal Findings, Legal Case Progression, and Outcomes in South African Rape Cases: Retrospective Review" 2009 PLoS Medicine 1; SAPS Crime Report (2012) 3; Conradie and Tanfa "Adjudication of Child Victims of Rape and Indecent Assault in Gauteng" 2005 Child Abuse Research in South Africa 4-5.

6 Conradie and Tanfa 2005 Child Abuse Research in South Africa 4-5.

7 See, eg, studies by Heger et al "Children Referred for Possible Sexual Abuse: Medical Findings in 2384 Children" 2002 Child Abuse \& Neglect 645-659; Kellogg et al "Genital Anatomy in Pregnant Adolescents: 'Normal Does Not Mean Nothing Happened'" 2004 Pediatrics 67-69; Christian et al "Forensic Evidence Findings in Prepubertal Victims of Sexual Assault" 2000 Pediatrics 100-104; Palusci et al "Medical Assessment and Legal Outcome in Child Sexual Abuse" 1999 Arch Pediatr Adlesc Medi 388-392; Bays and Chadwick "Medical Examination of the Sexually Abused Child" 1993 Child Abuse Neglect 91110; and Adams et al "Examination Findings in Legally Confirmed Child Sexual Abuse: It's Normal to be Normal" 1994 Pediatrics 310-317.

8 Kreston "An Inconvenient Truth: On the Absence of Definitive Corroborative Medical Evidence in Child Sexual Abuse Cases" 2007 Child Abuse Research in South Africa 93.

9 Bagshaw "Behavioural Science Data in Evidence Teaching and Scholarship" in Roberts and Redmayne (eds) Innovations in Evidence and Proof (2007) 219. 
prosecutions, Steel describes it as testimony from psychiatrists, psychologists and social workers who have experience in dealing with sexually abused children. ${ }^{10}$ BSE can serve two purposes - as substantive or diagnostic evidence in determining the issue of whether or not CSA occurred and as background evidence in providing a context within which to evaluate the evidence of the ACSA victim. The substantive role of BSE is discussed first.

All too often, the definition of substantive or corroborative evidence in CSA cases is too narrow. Despite the prevalence of observable psychological and emotional findings among CSA victims, the inordinate faith placed in medical examination findings often causes criminal justice systems to fail to locate substantive and corroborative evidence in the unusual behavioural reactions of these children. There is no standard pattern of emotional and psychological reaction to CSA, as reactions vary among children. Equally, the emotional and psychological reactions may be too general that they are not necessarily compatible with CSA. However, McCord justifiably warns against the tendency to brand evidence as irrelevant, merely on account of its generality. ${ }^{11}$ McCord observes that generalised evidence remains relevant because of its tendency to make the issue of determination more probable than it would have been without the evidence. Faust equally makes the point that when dealing with BSE, the "central aim is to cut into or reduce the level of uncertainty ... anything that reduces the level of uncertainty is good". ${ }^{12}$ Myers et al add that when evidence based on observed behavioural and psychological reactions is coupled with the child's accurate testimony on the occurrence of CSA, the probative value of this evidence increases. ${ }^{13}$ Thus, some observed emotional and behavioural effects of CSA may be generalised. However, evidence based on these reactions remains relevant in increasing the accuracy of Courts when determining the issue of whether or not CSA occurred.

Moreover, in addition to more generalised reactions, there are some behavioural and psychological reactions that tend to be more probative of CSA. For instance, behaviour such as age-inappropriate sexual behaviour and knowledge stand out as more probative of CSA. Friedrich et al explain that with younger children, symptoms of a sexual nature have a strong nexus with sexual knowledge. ${ }^{14}$ The authors persuasively contend that symptoms such as aggressive sexuality in young children, imitation by young children of adult sexual acts, and sexual knowledge that is unusual for the age of a particular child are generally demonstrative of sexual knowledge and behaviour.

10 Steele "Expert Testimony: Seeking an Admissibility Standard for Behavioural Science in Child Sexual Abuse Prosecutions" 1999 Duke LJ 933-973.

11 McCord "Syndromes, Profiles and Other Mental Exotica: A New Approach to the Admissibility of Non-traditional Psychological Evidence in Criminal Cases" 1987 Oregon LR 79 and 80.

12 Faust "Holistic Thinking is Not the Whole Story Alternative or Adjunct Approaches for Increasing the Accuracy of Legal Evaluations" 2003 Assessment 432.

13 Myers et al "Expert Testimony in Child Sexual Abuse Litigation 1989 Nebraska LR61.

14 Friedrich et al "Normative Sexual Behaviour in Children" 1991 Pediatrics 462. 


\section{THE ROLE OF BSE IN PROVIDING A CONTEXT WITHIN WHICH TO EVALUATE THE EVIDENCE OF CSA VICTIMS (REHABILITATIVE EVIDENCE)}

Aside from BSE constituting a form of substantive evidence as discussed above, it can also provide a context within which to evaluate the evidence of CSA victims. Child sexual-abuse victims tend to exhibit unusual behavioural reactions which often seem perplexing to the average person. Lonsway ${ }^{15}$ provides a broad catalogue of behaviour that is often deemed deviant, including failing to fight or otherwise physically resist during the assault, experiencing "frozen fright" during the assault, delaying a report to the police or reporting only under pressure from family or friends, failing to recall or deliberately omitting specific details about the assault, being unable to identify the perpetrator to police, denying or minimising the assault to friends and family members, exhibiting no apparent emotional expression following the assault, exhibiting a loss of memory for events preceding the assault, providing apparently inconsistent statements at different points in time, having a relationship with the perpetrator prior and subsequent to the assault, blaming themselves for the assault and recanting. These reactions are deemed unusual or deviant because they often seem inconsistent with the stereotypical reactions of CSA victims. Equally, these behavioural reactions generally create the impression that the child's allegations are false.

Unexplained deviant behavioural reactions cast doubt on the testimony of the child victim, often rendering children less credible. Given that in most CSA cases, there are no eyewitnesses, the testimony of the child complainant often forms the crux of the prosecution case. Where the testimony of the child victim is impeached based on unexplained deviant behavioural reactions, most likely it is unsafe to found a conviction based on such the child's testimony. Sinnott has observed that for the defence, unusual behavioural reactions often turn out to be evidential material to make the case for the defence. ${ }^{16}$ The defence is released of the duty to adduce its own evidence and instead focuses solely on the CSA victim's unusual behavioural reactions. Myers et al note that, while the CSA victim's credibility based on unusual behaviours is legitimate, it becomes questionable when the defence concentrates on these unusual reactions to disprove CSA. ${ }^{17}$

In light of the above circumstances, BSE becomes relevant in providing a background or proper context within which to evaluate the evidence of the CSA victim. The opinion of an expert, explaining the circumstances surrounding the seemingly unusual behaviour of the CSA, merely provides a contextual background. Unlike the role of BSE as discussed in the previous section, BSE for contextual purposes has no probative value in the determination of the issue of whether or not CSA occurred.

15 "The Use of Expert Witnesses in Cases Involving Sexual Assault" 2005 Violence Against Women 11.

16 Sinnott "When the Defendant Becomes the Victim: A Child's Recantation as Newly Discovered Evidence" 1993 Cleveland LR 569-598.

17 Myers et al 1989 Nebraska LR 86. 
Overall, there is a general tendency to assess CSA solely with reference to physical evidence. However, BSE from behavioural science experts can be forthcoming in explaining the psychosocial dynamics of an abusive relationship, dispelling the myths about abuse and also explaining the often "invisible traits and manifestations of abuse". ${ }^{18}$

\section{THE POSITION IN SOUTH AFRICA WITH REFERENCE TO SELECTED RECENT CASE LAW}

Although the admission of BSE in CSA prosecutions is a rare phenomenon in most criminal justice systems particularly in Africa, South Africa's system has, to its credit, over the years admitted BSE in CSA prosecutions. Some of the more recent cases in which this nature of evidence was admitted are discussed below to demonstrate the critical role that the expert evidence played in these cases and to identify possible gaps in the approach of the Courts.

\section{Mdletye $v$ State $^{19}$}

This case pertained to the offence of incest between the appellant and his daughter, the complainant. The complainant grew up under the care of her grandmother. Towards the beginning of 1993, the complainant went to live with the appellant where she attended school. The complainant's allegations against the appellant were that a few months after she came to live with him in 1993, the appellant asked her to rub his back, and that he used to fondle her body including her genitalia. That the appellant later started having sexual intercourse with her regularly, three to four times a week. This state of affairs allegedly continued consistently from 1993 when she came to live with the appellant to 1996 when she reported the abuse to her aunt. In 1994, the complainant ascertained that she was pregnant. The appellant allegedly arranged for her to undergo an abortion which was conducted at home. The complainant alleged further that after the abortion, the appellant continued to have sexual relations with her. According to the complainant, the appellant's attitude towards her was one of possessiveness. The appellant sometimes severely assaulted her particularly because of her relationship with other men. It was the complainant's testimony that the appellant threatened to commit suicide or to kill himself if the complainant disclosed the sexual activities. The appellant, however, denied all the sexual-abuse allegations. The beating, he argued was moderate chastisement that he was entitled to perform like any reasonable parent. The credibility of the complainant was justifiably attacked. With respect to her evidence, it was established that whereas she had earlier stated that the appellant was the only person with whom she had sexual relations between 1993 and 1996, it emerged that she had sexual intercourse with other men on several occasions within this period.

18 Stevens "Unravelling the Entrapment Enigma: Reflections on the Role of the Mental Health Expert in the Assessment of Battered Woman Syndrome and Coercive Control Advanced in Support of a Defence of Non-pathological Criminal Incapacity (1)" 2011 THRHR 448.

19 Mdletye $v$ State $(246 / 98)$ (1999) ZASCA 77. 
Two experts adduced evidence pertaining to the complainant's behavioural and traumatic reactions. One of the expert witnesses, a qualified and experienced social worker trained to observe and assess complainants in child-abuse cases pointed out a number of symptoms displayed by the complainant. ${ }^{20}$ The complainant lacked concentration which resulted in a deterioration of her school work. ${ }^{21}$ The complainant also had nightmares. ${ }^{22}$ This expert opined that in her view, the complainant was manipulated by the appellant to such an extent that it was not surprising that she kept the sexual abuse to herself for three years. ${ }^{23}$ The expert pointed out that the complainant's decision to later run away from home was a common occurrence among child-abuse victims. The second expert witness, with a master's degree in clinical psychology and experience working with child abuse victims for years, equally proffered opinion. ${ }^{24}$ The second expert testified that her interview with the complainant indicated that the complainant displayed symptoms, all consistent with her version of what occurred between her and appellant. These included tension headaches, poor sleeping, poor appetite, poor concentration at school and forgetfulness.

In its judgment, the Supreme Court amongst others, ruled that the evidence of the two experts provided support for the complainant's version. ${ }^{25}$ The Court pointed out that the complainant's symptoms may be genuine as these symptoms were equally observed by the complainant's aunt. ${ }^{26}$ The Court therefore took cognisance of the fact that the complainant was a traumatised young person. ${ }^{27}$ The Court, however, reasoned that these symptoms could not exactly be traced back to the appellant's sexual activity with the complainant.

Ultimately, the conviction and sentence were set aside partly because of the grave inconsistencies in the complainant's testimony. This was indeed warranted in light of the grave inconsistencies. Generally speaking, it is commendable as the Court in this case admitted BSE by the experts. Indeed, in this regard, Melunsky AJA, specifically noted as follows:

"I will assume, in favour of the state, that the conclusions drawn by the [expert] witnesses are admissible in evidence. It nevertheless remains the function of the court to decide upon the weight to be given to their views for we are not inexorably bound by what witnesses have said or the opinions which they have expressed.'

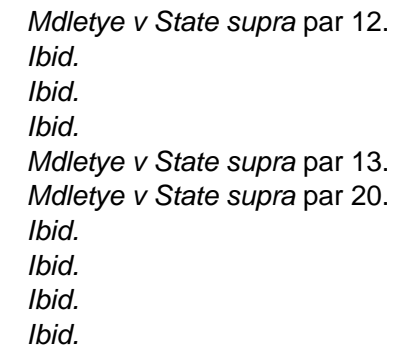




\section{Godi $v$ The State ${ }^{30}$}

The 2011 case of Godi $v$ The State pertained to the offence of rape. The facts of the case were that the appellant lived with her grandmother. The appellant worked in a tuck shop close to where the complainant and her grandmother stayed. As such the appellant and the complainant were acquainted with each other. The complainant testified about the alleged rape, stating that the rapes, on more than one occasion, took place on Fridays (in 2001) when her grandmother was away. According to the complainant, on the first occasion of the rape occurrence, the appellant invited her into her room and told her to undress upon which he had sexual intercourse with her. The following occasion was when the appellant asked her to wash dishes. It is not clear when the abuse was first reported. The facts, however, indicate that a report was not made immediately after the first alleged rape. In 2008, the appellant was convicted by the Regional Court and accordingly sentenced to 15 years' imprisonment. The appellant appealed against sentence and conviction in the High Court.

On appeal, pertaining to the testimony of the complainant, the defence submitted that her evidence was unreliable, contained contradictions and did not establish the offence that the appellant was charged with. ${ }^{31}$ The defence submitted further that the learned trial magistrate had misdirected himself in relying upon the evidence of the expert called by the prosecution to adduce BSE.

In the proceedings at the Regional Court, the prosecution called an expert to adduce BSE. The expert, an educational psychologist, evaluated the complainant on 4 May 2005 when she was 15 years of age. Amongst other sources, the expert had regard to a trauma report prepared by a welfare worker which was dated 26 March 2001 as well as a letter by an educational psychologist dated 2 June 2005. These two latter documents did not form part of her written record and were equally not included in the record. The report of the welfare officer, dated 26 March 2001, had reported that "there were objective symptoms of traumatization possibly as a result of sexual molestation, in the form of enurese, sleep disturbances ..."33

With regard to the expert's reference to these documents, the defence argued on appeal that such reference fell foul of the principles pertaining to admissibility of expert evidence as set out by Satchwell J, in Holtzhausen $v$ Roodt. ${ }^{34}$ Amongst others, the principles in the Houltzhausen case underscore that the expert's opinion should be based on admissible evidence and should not usurp the role of the Court. The defence accordingly submitted that the expert's evidence was inadmissible because the expert's opinion was based on inadmissible evidence and equally usurped the role of Court. ${ }^{35}$

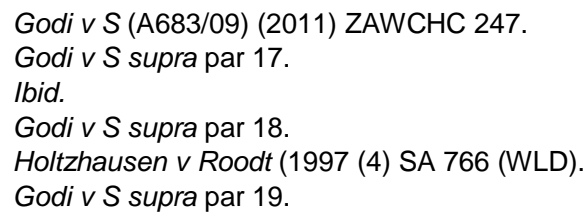


For what it is worth, the authors submit that Olivier $\mathrm{J}$, provides one of the instructive approaches to the rules of evidence in admitting BSE in CSA cases. Olivier J's approach is an exceptionally thoughtful and creative approach, one that the authors think best does justice to the complexity of the goal of fully exploiting BSE in CSA cases. In addressing the objection by the defence, Olivier J, categorically ruled that the expert was obliged to have regard to both documents. ${ }^{36}$ Although the expert had indeed consulted the two documents without their being admitted in evidence, the expert was extensively cross-examined on the results and conclusions drawn in these documents. ${ }^{37}$ The Court added further that

"the fact that the expert drew inferences also as to veracity and truthfulness [of the complainant] does not by itself make the evidence inadmissible - a court is bound to itself examine the facts - which may include expert opinion of the witness - and to draw its own conclusions". ${ }^{38}$

In affirming the role of BSE in providing a context within which to evaluate the evidence of the CSA complainant, the Court ruled that the expert gave important evidence with regard to the perception of events by the complainant, both at the time they took place and the time at which the complainant testified. ${ }^{39}$ More specifically, the Court pointed out that the evidence of the educational psychologist was important in informing the Court's decision on the competence and truthfulness of the rape itself. ${ }^{40}$ Without further elaboration, the approach of the Court in this case demonstrates the critical role that BSE played in providing background information and the appropriate context within which to evaluate the CSA victim's testimony. Again, this is not to suggest that BSE should be accorded due weight in all cases even when it is less relevant. Indeed, judges should discard BSE that is not properly substantiated and less relevant. However, the archaic rules of exclusion, by themselves, should under no circumstance constitute a justification for relevant BSE to be excluded or accorded less weight. BSE should only be excluded and accorded no weight after judicial officers have addressed their minds to the broader roles of BSE in CSA cases and weighed it against all the other evidence on record.

\section{$43 \quad S \vee$ The State ${ }^{41}$}

The case of $S v$ The State pertained to the offence of rape. The facts of the case were that between 2001 and 2002, the appellant allegedly raped his daughter, the complainant who was 12 years of age at the time. During trial in the Regional Court, the complainant testified against her father, recounting three cases of rape. The first, she said, took place in Glenharvie when she was in Grade 4 and 12 years old (something must be wrong: she was either about 9 and in Grade 4 or 12 and in Grade 7). The second, she said, took

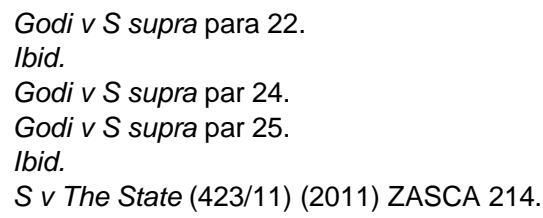


place at their home in the Newcastle Flats in Lucas Street which one may surmise, if the record is read purposively, is in Rustenburg while she was in Grade 7 (which would, on the probabilities, have been during 2001). The third, according to her evidence, took place at their dwelling in Van Zyl Street, Rustenburg, when she was in Grade 8 (which was during 2002). All three rapes allegedly took place under similar circumstances (the complainant was in bed, her mother was elsewhere, the appellant undressed her, she resisted but was overpowered and the appellant had intercourse with her). The appellant was convicted in the Regional Court on a charge of rape. He was sentenced to 15 years' imprisonment. The conviction and sentence by the Regional Court was confirmed by the High Court. The appellant appealed against conviction and sentence in the Supreme Court. At trial in the Regional Court, the complainant's allegations were denied by the appellant and in the end, the magistrate was confronted with conflicting versions: that of the complainant and the denial of the appellant. Thus, on appeal in the Supreme Court, the only issue in the case was whether the appellant had raped the complainant, not whether she had been raped or sexually molested.

At trial in the Regional Court, the prosecution called an educational psychologist, who interviewed the complainant and formed certain impressions about her. ${ }^{42}$ The gist of her evidence as summarised by the magistrate was that the complainant was unwilling to cooperate or communicate, that she blamed herself for causing a rift in the family, that she was emotionally unstable and lacked confidence and that she hated her father because he was always drunk. As a matter of fact, the information that the psychologist had obtained from the complainant was that she had been raped while she was in Grade 4. The expert's report did not contain any reference to other instances of rape.

There were similarly inconsistencies in the complainant's evidence. The complainant's statement to the police, dated 30 October 2001, recorded one instance of rape only. Since the complainant was immediately removed from parental care, it was difficult to understand how the third rape could have occurred during 2002. Although the magistrate at the Regional Court was aware of these inconsistencies, she relied on the evidence of the education psychologist in corroboration of the fact that the appellant was the culprit. The Supreme Court, in hearing the appeal, ruled that the education psychologist's evidence could in no way contribute to the determination of the issue in question - as to whether the appellant had raped the complainant. ${ }^{43}$ The appeal was accordingly upheld and the conviction and sentence set aside.

In light of the outcomes of the apparent case, the inevitable question one might ask is whether BSE was appropriately dealt with by the Court. Of note, it is commendable that just as the position was in the Godi case and the Mdletye case, the Court in the S case admitted BSE as advanced by the education psychologist. However, having weighed the evidence of the expert along with the entire evidence on record, the Supreme Court found that the expert's opinion was not relevant to the issue of determination before the Court. Can the Court then be faulted for this position? Certainly not.

$42 \quad S v$ The State supra par 12.

${ }^{43} \quad S v$ The State supra par 17. 
Conversely, the approach of the Court in this case underscores the need for the Courts when dealing with BSE to consistently weigh it against all the other evidence on record. It does not necessarily follow that all admitted evidence should be accorded full weight. As Zeffertt and Paizes have rightly pointed out, relevance as a criterion of admissibility of evidence is "a matter of reason and common sense", with its foundation based on the facts, circumstances and principles of each particular case. ${ }^{44}$ Thus, although the need to accord due weight to BSE is underscored, where BSE, having been weighed against all the evidence on record fails to fit in with the other evidence on record, then the evidence shouldn't be accorded weight at all.

However, what is puzzling about Harms J's opinion in the S case is the strength with which traditional legalist ideas about the admissibility of expert evidence continue to inform his thinking, despite his earlier demonstration of readiness to accommodate BSE. In substantiating on the rules of expert evidence, the Court was seemingly inspired by some of the outdated rules on exclusion of expert evidence which, if dogmatically applied, could lead to less weight being accorded to relevant BSE. Harms J, made reference to the case of $S \vee$ Engelbrecht, ${ }^{45}$ wherein Satchwell J, stated as follows:

"Courts frequently turn to persons with expertise and skill for assistance. The relevant principles applicable to the admissibility of opinion evidence by experts, including psychologists and social workers, have been set out in numerous authorities. Firstly, the matter in respect of which the witness is called to give evidence should call for specialised skill and knowledge. Secondly, the witness must be a person with experience or skill to render him or her an expert in a particular subject. Thirdly, the guidance offered by the expert should be sufficiently relevant to the matter in issue to be determined by the Court. Fourth, the expertise of any witness should not be elevated to such heights that the Court's own capabilities and responsibilities are abrogated. Fifth, the opinion offered to the Court must be proved by admissible evidence, either facts within the personal knowledge of the expert or on the basis of facts proven by others. Sixth, the opinion of such a witness must not usurp the function of the Court."

Thus, in the $S$ case, the Court concluded that the evidence of the behavioural-science expert did not satisfy requirements four, five or six. ${ }^{46}$ It suffices to re-echo that requirement six pertains to the evidence of the expert not usurping the function of the Court by opining on the ultimate issue. The problem with Harms J's argument here is the untenable assumption that the ultimate issue rule usurps the role of the Court. It is submitted that arguments based on expert evidence having the effect of usurping the function of the Court are out of step. There is a formidable volume of literature demonstrating the outdatedness of this rule. Wigmore has persuasively argued that it is a "bit of empty rhetoric" as the Court is not bound by the opinion of the expert. ${ }^{47}$ Zeffertt and Paizes indicate that this formulation serves no purpose other than "obfuscate the true principle". ${ }^{48}$ Morgan termed the rule "sheer nonsense", ${ }^{49}$

44 Zeffertt and Paizes The South African Law of Evidence (2009) 340.

$45 S$ v Engelbrecht 2005 (2) SACR 41(W) par 26.

$46 \quad S \vee$ The State supra par 19.

47 Wigmore Treatise on the Law of Evidence (1940) 1920.

48 Zeffertt and Paizes The South African Law of Evidence 315.

49 Morgan Basic Problems of Evidence (1962) 45-50. 
while McCormick stated that the rule is "unduly restrictive, is pregnant with close questions of application and often unfairly obstructs the party's presentation of his case". ${ }^{50}$ Thus, it is apparent that, although generally, BSE is admitted in CSA prosecution, there is some sort of inconsistence in the approach of the Courts to the rules governing the admissibility of this nature of expert evidence. The inappropriate application of the rules could potentially lead to the exclusion of BSE or account for the less weight being accorded to the admitted BSE.

Thus, although the existing trend of the Courts in South Africa should not be underestimated, there is obvious room for improvement. And arguably, there is reason for South Africa to look beyond the borders of its legal system. The approach by the Courts in America could be of useful insight in this regard.

\section{THE POSITION IN THE UNITED STATES OF AMERICA WITH REFERENCE TO SELECTED CASE LAW}

The courts in the USA, like South Africa's courts, have over the years admitted BSE in the prosecution of CSA cases. Two selected decisions from the courts in the USA are discussed with a view of establishing whether South Africa should do more to ensure that BSE is fully exploited in CSA prosecutions.

\section{People v Beckley ${ }^{51}$}

The appellant was charged and convicted of the offence of criminal sexual conduct in the first degree with the complainant, fifteen-year-old daughter. According to the complainant's testimony at trial, on 29 May 1983, she was watching television at her father's trailer, where she resided following her parents' divorce. Her father joined her when he arrived home. During this time he rubbed her back and kissed her several times. The appellant then went to his room but later called for her. He asked her to lay down with him for a while and then grabbed her onto his bed. While holding down her arms, the appellant unclothed his daughter and had sexual intercourse with her. At the appellant's demand, she promised to keep the incident a secret. After washing and dressing, the complainant phoned her mother and reported her father's "passes", but never mentioned intercourse. The complainant's testimony indicated that she initially declined her mother's offer to pick her up, but called back immediately and accepted. She never mentioned intercourse to her mother. The complainant's testimony further indicated that the following year, in 1984, she told various people about accused's advances, but made no mention of the intercourse. She resumed visits with her father after the incident. She did not reveal the act of intercourse until approximately one year later (1984) when she wrote about the incident in a journal for a high school

50 McCormick Handbook of the Law of Evidence (1954) 12.

51 People v Beckley, 161 Mich. App. 120, 409 N.W.2d 759 (1987). 
English assignment. ${ }^{52}$ After the first allegations reported to the mother, no action was taken because the complainant retracted the allegations she made to the mother a few days later.

The appellant denied any act of intercourse, but admitted to kissing his daughter and inviting her to bed. He explained that it was a way to see if his daughter was sexually active. On cross-examination of the complainant, defence counsel attacked the truth of her allegations by implying that her post-attack behaviour was not consistent with a victim of sexual abuse. ${ }^{53}$ The defence cited her postponed reporting (a year after the incident), means of reporting, continued contact with the accused, and initial denial of intercourse as indications that no sexual intercourse actually occurred. The prosecution tried to restore the complainant's credibility with the testimony of a mentalhealth expert, a certified social worker, who had previously examined the complainant. The expert possessed a double master's degree in psychology and education. The Court limited the expert's testimony to the observed behaviour of the complainant which was in accord with those of an incest victim. The Court allowed the expert's testimony during the prosecution's case in which she testified that there are certain behaviours recognised in psychiatric literature among sexually-abused children. The patterns discussed were: (1) the delayed disclosure in the school journal, (2) the medium of disclosure, that is, to a non-family member through an impersonal writing, (3) the daughter's continued desire to see the alleged offender and (4) the daughter's initial tendency to deny to others the occurrence of the sexual intercourse. ${ }^{54}$ The expert stated that each of these patterns, and all of them taken together, were consistent, rather than inconsistent, with a child who had been sexually abused..$^{55}$ She identified the causes, documented in literature of the field, for each of these apparently incongruous behaviour patterns in an abused child. ${ }^{56}$ On cross-examination, defence counsel questioned the complainant's failure to remember conversations that she had had about the event. This, the expert explained, was typical of a victim trying to minimise the event, and did not necessarily indicate fabrication. ${ }^{57}$ She testified that this was not inconsistent with commonly observed behaviours. ${ }^{58}$ Additionally, she stated that a bitter divorce, a spiteful mother, and resentful feelings between the appellant and the complainant did not rule out sexual abuse, but would need to be examined. ${ }^{59}$

The appellant appealed against the decision of the Trial Court, arguing amongst others that the expert's testimony should not have been admitted. The appellant stated that this was a kind of scientific evidence which did not meet the standard required for expert testimony and that the expert vouched for the credibility of the complainant, consequently going so far as to suggest

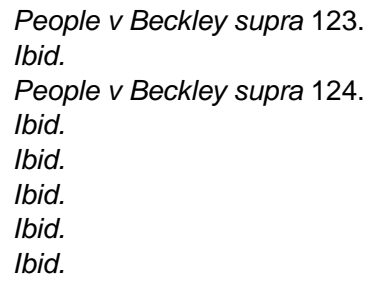


that the assault actually occurred. ${ }^{60}$ In addressing the objection raised by the defence, the Court made reference to Rule 702 of Michigan Rules of Evidence (MRE) which provides as follows:

"If the court determines that recognised scientific, technical, or other specialised knowledge will assist the trier of fact to understand the evidence or to determine a fact in issue, a witness qualified as an expert by knowledge, skill, experience, training, or education, may testify thereto in the form of an opinion or otherwise."

Consequently, the Supreme Court of Michigan affirmed the conviction and sentence by the Trial Court. ${ }^{61}$

It can be gleaned from this decision that there was no conclusive medical evidence whatsoever owing to the delay in making the report. As such, the testimony of the complainant formed the crux of the prosecution case. Incidentally, the complainant's testimony was marred with inconsistencies. These inconsistencies were, however, explainable. The detailed opinion of the expert demonstrates the critical role of BSE in CSA prosecutions. Strikingly, in addressing the objection to the expert's opinion, the Court more readily made reference to the codified rules of evidence as provided for in the MRE.

\section{State $v$ Myers $^{62}$}

In this case, Myers, the appellant was charged and convicted of the offence of criminal sexual conduct in the second degree with a complainant under 13 years of age contrary to section 609.343(a) of the Minnesota Statute. Pursuant to the judgment of conviction, Myers was sentenced to a 35-month term of imprisonment. The facts of the case were that between August 1980 and July 1981, Myers, the appellant and accused at trial, had criminal sexual contact with the young daughter of the woman with whom he was living (the complainant). The facts indicated that one morning in either November or December of 1980, when the complainant was seven years old and while Myers was preparing breakfast in the kitchen of their two-story home, he told the complainant to go downstairs from her bedroom to help him. The complainant initially refused but complied when Myers threatened to spank her. The facts indicated further that on that morning, the complainant's mother was in bed when Myers called the complainant. Because it was quite dark downstairs, the complainant's mother got out of bed to see what was happening. When she arrived downstairs, Myers was sitting on the living room sofa and her daughter was standing directly across the room in the doorway between the living room and kitchen. The mother took the complainant upstairs to her bedroom and asked her what had happened. The complainant first responded that she did not know, but ultimately she said that Myers did things to her like he did to her mother. The mother then confronted Myers who said he did not know what the complainant meant. It was not, however, until several months later, on 15 September 1981, when the complainant's maternal uncle contacted the St Louis County Department of Social Services,

60 People v Beckley supra 125.

61 People v Beckley supra 131.

62 State v Myers, 359 N.W.2d 604 (Minn. 1984). 
that the authorities were notified of the possibility of abuse. On the following day a Social Worker talked to the complainant at her school. During the course of the conversation between the complainant and social worker, the complainant informed the social worker that the appellant would sometimes come into her bedroom at night and touched her on her "chest" and between her legs. ${ }^{63}$ Upon further questioning by the social worker, the complainant detailed the manner in which Myers molested her. ${ }^{64}$ The social worker's session with the complainant led her to the conclusion that the appellant had commenced abusing her when she was six and that the child could not conceptualise the difference between sexual penetration and contact. On 6 October 1981, formal charges were filed against Myers. The complainant's mother and the social worker testified in affirmation of these facts. Further, the complainant, who was eight years old at the time of the trial, also testified and substantially repeated her earlier statements to the mother and the social worker.

To prove its case, the prosecution adduced the evidence of an expert in behavioural sciences. The expert had a doctorate in psychology, as well as experience in dealing with familial sexual-abuse cases. The expert testified that commencing on 11 December 1981, she saw the complainant on seven occasions in sessions each lasting at least one hour. ${ }^{65}$ The expert stated that in each of these sessions, the complainant related the manner in which accused abused her and that, while she continually added information, the child's allegations remained consistent. ${ }^{66}$ At trial, the complainant repeated the statements she made to the expert. The expert related what the complainant had told her about the breakfast-time incident and other occasions of sexual abuse, and she testified that the complainant's allegations had remained consistent throughout their several meetings. In addition, the expert testified to the uniqueness of child sexual offences perpetrated by known persons, stating that this kind of abuse ordinarily goes on for a long period of time. ${ }^{67}$ Unlike most crimes, it is unusual for it to occur only on a single occasion. ${ }^{68}$ The expert was permitted to describe characteristics or traits typically observed in sexually-abused children. In this regard, the expert testified that she observed these general characteristics in sexually-abused children. She explained that fear causes the child to be afraid to tell of the abuse because she fears she will be blamed or punished, fears of possible break-up of the family and disbelief by others. ${ }^{69}$ The expert further testified that victims of sexual abuse are often confused, particularly young children. ${ }^{70}$ Because of the child's confusion, shame, guilt and fear, disclosure of the abuse is often delayed. ${ }^{71}$ When the child does complain of sexual abuse, the mother's reaction frequently is disbelief, and she fails to report the

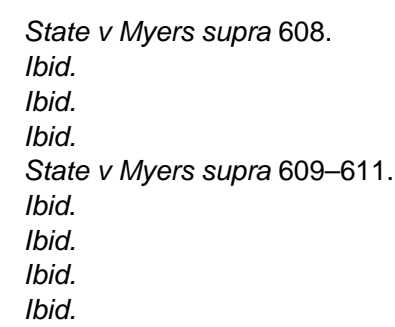


allegations to the authorities. ${ }^{72}$ The expert also described the symptoms and emotional conditions she observed in the complainant which could have resulted from the sexual abuse. ${ }^{73}$ These were more specific individual characteristics, including fear of men, nightmares that have an assaultive content, sexual knowledge unusual in a child of the patient's age and ageinappropriate behaviours. She then identified those characteristics commonly exhibited by sexually-abused children which she had observed in the complainant. ${ }^{74}$

The appellant testified at trial, denying the allegations of sexual abuse against the complainant. The appellant's denial was rejected by the trial court, and the appellant was convicted and sentenced to a 35-month term of imprisonment, hence the appeal to the Supreme Court of Minnesota. The Memorandum of Appeal raised several grounds of appeal, amongst which are that the Trial Court erred in admitting expert psychological testimony describing the behaviour and symptoms typically exhibited by sexually abused children, and expressing the opinion that the complainant's allegations were not fabricated.

On appeal in the Supreme Court of Minnesota, the Court dealt with the objection as follows: The Court commenced with an inquiry into the propriety of admitting the expert's testimony. On this issue, the Court ruled that the admission of an expert's opinion generally rests within the discretion of the Trial Court. In this regard, the Court ruled that the expert was sufficiently qualified to render an opinion with respect of the emotional and psychological characteristics often observed in children who are victims of sexual abuse. ${ }^{75}$ In addition to her educational qualifications, the expert had significant practical experience in dealing with sexually abused children. The Court concluded that the expert's testimony, in which she described the traits and characteristics typically found in sexually abused children and those she had observed in the complainant was helpful. ${ }^{76}$ The Court categorically pointed out that there can be no doubt that an indirect effect of that portion of the expert's testimony was to bolster the complainant's credibility. The Court, however, noted that such a fact, by itself, does not render the testimony inadmissible. The Court emphasised that the test is not whether opinion testimony embraces an ultimate issue to be decided by the Court, but whether or not the expert's testimony, if believed, will help the Court to understand the evidence or to determine a fact in issue. ${ }^{77}$ In substantiating further on the role of BSE, the Court pointed out that the nature of the sexual abuse of children represents a less than adequate foundation for assessing the credibility of a young child who complains of sexual abuse. ${ }^{78}$ The Court observed that by explaining the emotional antecedents of the victim's conduct and the peculiar impact of the 
crime on other members of the family, an expert can assist Court in evaluating the credibility of the complainant. ${ }^{79}$

Pertaining to the second segment of the expert's testimony that encompassed a description of the symptoms and emotional conditions she observed in the complainant (diagnostic evidence), the appellant contended that this part of the testimony was inadmissible because it was unreliable. The appellant averred that the conditions described by the expert were highly subjective and not necessarily the result of sexual molestation. In addressing this contention, the Supreme Court stated that the fact that the expert's observations of the complainant's psychological and emotional symptoms are not physically demonstrable does not justify the conclusion that they are not probative of CSA and as such, of no help to Court. ${ }^{80}$ The Court added that the cause of many physical and emotional ailments and even the existence of those conditions which are identified chiefly by subjective complaints cannot be demonstrated to an absolute certainty. They are, nevertheless, the subject of expert testimony. The relativity of expert-opinion testimony with regard to the existence or cause of the condition goes not to the admissibility of the testimony but to its relative weight. Further, as it pertained to the expert's opinion on the truthfulness of the complainant, the Supreme Court made reference to Rule 608(a) of the Minnesota Rules of Evidence, consequently finding that the rule removes an obstacle to the use of expert testimony concerning the veracity of a witness. ${ }^{81}$ Consequently, the decision of the trial court on conviction and sentence was affirmed by the Supreme Court.

\section{THE FACTORS THAT COULD ENSURE THAT BSE IS FULLY EXPLOITED IN SOUTH AFRICA IN LIGHT OF THE JURISPRUDENTIAL TREND ABOVE}

\section{According greater weight to BSE in CSA cases}

In the past years, the interface between psychology and psychiatry on the one hand and the law on the other hand was laden with conflict. In some cases, lawyers have "accused" experts in this field [BSE] of making overblown claims and willing to modify their testimony to serve social or financial motives ${ }^{82}$ Bersoff once said this of experts in psychology: "In our courtroom, psychology is still seen as a mysterious inexact discipline ... populated by hired guns who will switch sides and proffer opinions for the right fee and the greatest notoriety" ${ }^{83}$ Hagen went a step further to overdramatise the impact of psychologists in the courtroom in observing that their opinions are full of "anecdotes, errors, flaming overgeneralisations, and inflammatory charges" ${ }^{84}$ Hagen in fact suggested that justice systems should "throw the experts out".

Ibid.

Ibid.

Ibid.

82 Brigham "What is Forensic Psychology, Anyway?" 1999 Law \& Human Behaviour 285.

83 Bersoff "Preparing for Two Cultures: Education and Training in Law and Psychology" in Roesch and Hart (eds) Psychology and Law: The State of the Discipline (1999) 401.

84 Hagen Whores of the Court (1997) xiii. 
Admittedly, over the years, criminal justice professionals have changed and continue to change their attitudes towards BSE and the experts in this field. However, the legal culture of some justice systems continues to be relatively conservative or less accommodative of BSE. Klare has argued that "legal culture has a powerful steering or filtering effect on interpretive practices, therefore on adjudication, and therefore on substantive legal development". ${ }^{55}$ As such, sometimes the scepticism of some judicial officers may impact negatively on the interpretation and weight accorded to BSE.

Strictly speaking, the approach to BSE by the courts in both South Africa and America is similar in terms of doctrine and principle. In both systems, the Courts admit BSE in CSA prosecutions. However, although both criminal justice systems are admitting BSE in CSA prosecutions, seemingly, the courts in the USA are more accommodative of BSE and equally according greater weight to it than the courts in South Africa. The point here is not that the approach of the USA is right and that of South Africa is wrong, as it pertains to the manner in which BSE is dealt with. It is that judicial officers in South Africa's courts need to be more accommodative of BSE and equally embrace the broader roles that BSE can play in CSA cases. Greater accommodation of BSE and its broad roles will seemingly impact on its interpretation, application and consequently, the weight accorded to it.

Generally, when dealing with expert evidence, the court is not only faced with the task of determining which elements of experts' evidence must be disregarded as irrelevant or unimportant, but must also find means of determining the significance or weight that should be attached to expert evidence in any given case. If evidence is admissible in court, it can be presented and tested in court. ${ }^{86}$ "The court will then analyse the evidence to see how influential it may be. In other words, the court will decide how much weight to give to evidence. ${ }^{.87}$ A piece of evidence is admissible if it might assist the court in establishing a fact. ${ }^{88}$ It does not necessarily follow that once evidence has been admitted in court it will be given full weight. Weed observes that evidence may be given full weight, partial weight, more or less weight than other evidence, or no weight at all. ${ }^{89}$ Once the evidence has been admitted, it is the court's role to evaluate it to assess its weight. In doing this, firstly, the court must weigh up all the evidence as a whole. ${ }^{90}$ Secondly, having evaluated the evidence in question together the whole body of evidence adduced, the court must draw proper inferences. ${ }^{91}$

Needless to recite the facts of the cases discussed above, it could be argued persuasively that upon effectively weighing BSE against all the evidence on record, the courts in the USA are according greater weight to BSE than the case is in South Africa. As consistently noted, in both justice systems there has been an established practice of admitting BSE. However,

\footnotetext{
85 Klare "Legal Culture and Transformative Constitutionalism" 1998 SAJHR 179.

86 Bellengere et al The Law of Evidence in South Africa: Basic Principles (2013) 23.

87 Ibid.

88 Zeffertt and Paizes The South African Law of Evidence 237.

89 Weed "Weight of Evidence: A Review of Concept and Methods" 2005 Risk Analysis 1545.

90 Bellengere et al The Law of Evidence in South Africa: Basic Principles 28.

91 lbid.
} 
seemingly the interpretative methods of the courts in the USA are more accommodative of BSE. These interpretative methods are equally informing the nature of inferences drawn by the courts with regard to BSE. For instance, as opposed to generally limiting BSE to the role of providing a context within which to evaluate the evidence of the CSA victim, in the USA, the often ignored diagnostic role of BSE in informing the decision of the court on whether or not CSA occurred is being accommodated in cases where the evidence is properly adduced by qualified experts. This was evident in the Myers case. This is a slight departure from the position in South Africa where some scholars have gone a step further to recommend that BSE constituting substantive evidence that CSA occurred should not be accommodated. ${ }^{\text {gr }}$ This, they argue amounts to proffering an opinion on the ultimate issue which usurps the function of the court.

The above difference suggests that though both criminal justice systems proceed on the basis of similar doctrine and principles when dealing with BSE, the weight accorded to BSE varies. The impression created is that depending on the attitude of a judicial officer towards BSE, the judicial officer can indiscriminately switch between interpretive modes when evaluating admitted BSE. This is because a judge is not responsible for or extra-legally influenced in his choice of interpretive methods. Ostensibly, ingrained intellectual instincts and sensibilities, such as scepticisms about BSE and inordinate faith in the superiority of medical evidence over BSE, weigh so heavily on judicial officers, hence making it an issue of attitude. Therefore, unless judicial officers approach BSE with an attitude that accommodates its broader roles, it is less likely to be accorded the weight it deserves in CSA cases.

\section{Codifying the rules on admissibility of expert evidence to afford guidelines to criminal justice professionals in dealing with BSE}

Bellengere et al argue that the process or the interpretative methods that the court adopts in evaluating and assessing admitted evidence may well influence the final inferences drawn and consequently, weight accorded to it. ${ }^{93}$ Thus, the weight accorded to a piece of evidence may depend on the interpretative approach of the court. It is notable that it is hard to establish with certainty, the reasons behind the slight differences in approach of the courts in the USA and South Africa. It could, however, be argued persuasively that, where courts have some guidelines to work with as it pertains to the manner in which expert evidence is to be dealt with, more informed interpretation, assessment and inferences are drawn. Arguably, this could indirectly impact on the ultimate weight accorded to the admitted expert evidence.

In the USA, prior to the Federal Rules of Evidence of 1975, the interface between science and law was not adequately substantiated upon. Evidence scholars breathed a sigh of relief after their long-awaited advocacy for reform

92 See, eg. Songca "Aspects of Sexual Abuse of Children: A Comparative Study" 2003 Unpublished Doctoral Thesis, University of Pretoria 460-461.

93 Bellengere et al The Law of Evidence in South Africa: Basic Principles 28. 
yielded results with the adoption of the Federal Rules of Evidence in 1975. Until these issues were adopted through express substantiation in accordance with the Federal Rules of Evidence, scholarly and judicial divergence was apparent on the exact place and application of certain rules when dealing with expert evidence. The Federal Rules of Evidence therefore offered a relatively detailed interpretative guidance to judicial officers and other justice professionals in dealing with admissibility and weight of expert evidence. ${ }^{94}$ For instance, Rule 702, amongst others, addresses the issue of expert qualification and the ideal criterion of "helpfulness" in dealing with expert evidence. Rule 703 addresses the issue of basis of expert opinion, ultimately streamlining the exact place of hearsay in founding the opinion of experts. Rule 704 abolishes the rule against expert testimony on the ultimate issue, thus finally putting to rest the tendency to exclude or accord less weight to BSE on account of this archaic rule. Rule 706 expressly brings on board the issue of court-appointed experts. The critical role of Rule 706 cannot be emphasised enough in light of the fact that some prosecutors are not keen on calling upon behavioural-science experts to substantiate on behavioural issues in CSA cases.

Indeed the codified rules of evidence are merely an affirmation of the evolving common law. As such one could argue that there is no justification in codifying a system of law that continues to evolve. However, the codification of the rules of evidence, expressly discarding certain traditional rules of exclusion, such as the ultimate-issue rule, has seemingly guided the courts in dealing with BSE and as such, had a positive impact on the accommodation of BSE and the weight accorded to it. For instance, in the two cases discussed, namely, the Beckley case and the Myers case, the consistent reference of the courts to the codified rules of evidence was evident. The content of the Federal Rules of Evidence similarly affirms the greater detail with which the aspect of expert evidence is delineated upon. On the other hand, in the S case, faced with the objection of the defence on the ultimateissue rule and the expert's option, to base their opinion on inadmissible evidence, the Court ruled that the expert's opinion defied these rules. Presumably, if there was a codified system expressly delineating on the exact place of these rules when dealing with expert evidence, the Court would have adopted a different approach. South Africa's justice system does not necessarily have to enact legislation to this effect. A set of guidelines in place to further a smooth interface between the criminal-justice system and behavioural-science experts is in itself sufficient. At the very least, these guidelines should encompass some of the following aspects:

- Qualification of experts in BSE in CSA cases;

- the exact place and role of diagnostic and non-diagnostic standards in advancing BSE;

- ethical rules of conduct;

- therapeutic and forensic roles and the need to avoid dual roles;

- nature and scope of opinion in CSA cases;

94 See, eg, Daubert v Merrell Dow Pharmaceuticals, Inc., 113 S.Ct.2786 (1993). 
- objectivity, methodologies and appropriate techniques of assessment;

- confidentiality and informed consent in terms of the relationship between the CSA victim and the expert;

- the exact place of the traditional rules of exclusion such as the so-called ultimate-issue rule, amongst others.

\title{
63 Logical, sound and coherent explanatory power by experts advancing BSE
}

Emphasis on the need for courts to accord greater weight to BSE in CSA prosecutions is of little utility if the opinion of the experts is fundamentally flawed. "Without logical coherence no theory can command validity." If courts in South Africa are to accord greater weight to BSE in CSA cases, then behavioural-science experts will need to perform a more thorough task in advancing their opinion. Meintjes-Van der Walt has rightly observed that

\begin{abstract}
"[i]f the primary objective of expert evidence is to assist the court, then it follows logically that every attempt should be made, systemically and otherwise, to fulfil this purpose. This can only be achieved if the expert evidence is introduced to the criminal justice process in such a way as to optimally achieve this primary goal. Expert evidence can only be of assistance where it is presented in such a way as to illustrate the expert's evidence and not obfuscate his information. It is only when the expert succeeds in educating the trier of fact in respect of his (the expert's) particular field of expertise to a sufficient degree, that the court will be in a position to apply the expertise to the fair adjudication of the issues in dispute."
\end{abstract}

Undoubtedly, the explanatory power of the expert can profoundly impact on the weight accorded to their opinion. It is therefore critical for experts to educate the court in such a manner that the Court receives the appreciable help sought after in admitting the opinion of the expert. Foster and Huber rightly remark that

\begin{abstract}
"[h]ow a proposition is framed says much about how solid or slippery it really is. This is true in science as it is in ordinary discourse. Whether they come from children, politicians, judges, or scientists, plain, definite and straight-forward statements are more likely to be strong and sound than verbal circumlocutions, simply because plain lies and errors are so much easier to detect and knock down."
\end{abstract}

Moreover, there are persuasive arguments to the effect that courts generally accord little weight to broad generalisations. ${ }^{98}$ It is therefore critical for behavioural-science experts in CSA cases to give detailed reasons for their conclusions and an accurate account of the investigations that they carried out for the purpose of arriving at their conclusions. To further make their opinion more precise, preferably, the expert should make precise

95 Meintjes-Van der Walt "The Proof of the Pudding: The Presentation and Proof of Expert Evidence in South Africa" 2003 Journal of African Law 96.

96 Meintjes-Van der Walt 2003 Journal of African Law 95.

97 Foster and Huber Judging Science: Scientific Knowledge and the Federal Court (1977) 71.

98 Black et al "Science and the Law in the Wake of Daubert: A New Search for Scientific Knowledge" 1994 Texas LR 755-756. 
statements on the particular child assessed and how its unusual behaviour relates to the issue of determination before the court. This should be backed up by appropriate explanatory power. The existing literature and empirical studies on the subject should be of insight to the experts to aid them in effectively furthering the role of educating the court. The implication of logical consistency and explanatory power of experts on the ultimate weight accorded to their opinion can ably be seen in the two USA cases, the Beckley case and the Myers case. In these two cases, there is a clear indication of logical consistence and sound explanatory power. Reference was consistently made to existing literature on the subject in question, the experts made an effort to relate their findings to the CSA victim in question. There was greater detail in the manner in which their opinions were presented, seemingly leaving no room for assumption and speculation on the part of the court. The sound explanatory power of the experts ostensibly impacted on the extent to which the court dealt with and substantiated upon the opinion.

\section{CONCLUSION}

As the knowledge of the scientific community continues to grow exponentially in many areas of behavioural science, criminal justice systems will seemingly move forward into greater interface with science. The value of BSE will equally come to the fore in providing a better understanding of CSA and the CSA victim's behaviour. Additionally, amidst the paucity of medical evidence, it is possible that BSE will continue to constitute an indispensable tool in CSA prosecutions. It is commendable that South Africa has over the years admitted BSE in CSA prosecutions. However, if BSE is to be effectively exploited in CSA prosecutions, it is not enough for it to be admitted. It should equally be accorded full weight where it has effectively been weighed against all the evidence on record. It is particularly critical for courts to lay to rest the scepticism about psychology and psychiatry and to continually keep pace with developments which have the potential to improve the accuracy of their decisions in CSA cases. Since the interpretative methods applied in substantiating on the admitted BSE seemingly impact on the inferences drawn, a coherent framework that equips judicial officers with adequate interpretative guidance is arguably merited. But an even greater burden rests upon behavioural-science experts to ensure that their opinions are advanced in a more logical manner for the courts to draw from therefrom and appropriately apply these opinions in CSA cases. 